\title{
Impressions of a Physicist at the Geneva 'Atoms for Peace' Conference - September 1971
}

The Fourth Geneva Conference on the Peaceful Uses of Atomic Energy bears a strong family likeness to its predecessors, but belongs without doubt to a new generation. The official plan was to make it "of interest to public officials, economists and planners as well as to technologists". There are therefore not many papers which give technical data or break new scientific ground. The physics of fission reactors for power production is now so well understood that new information - however necessary for the optimization and profitability of the systems under development - will not lead to changes of perspective that are important to public officials, economists and planners. So, since power generating fission reactors realistically dominate the scene, there is not much "physics" as such to be found here.

The situation is only marginally different when we consider the other uses of fission reactors - production of isotopes, applications of radiation, research applications in the biomedical field, research by means of major reactors and accelerators. A steadily widening field of application and an impressive growth of technical and scientific competence in the developing countries does not amount to "new physics". The new and often exciting physics carried out in the neutron beams and beams of charged particles made available by atomic energy programmes is now reported in the appropriate conferences on nuclear physics, solid or liquid state conferences, and not in this venue.

The work on fusion reactions and plasma physics has been surveyed and summarized. Very substantial progress is reported and I. Rabi was heard to say in a public interview that he felt it had moved "from the unlikely to the doubtful". But the masses of excellent work, much of it performed under exemplary conditions of international collaboration, were of course destined to be summarized in a few sentences here, and a paragraph or two there. Again the science is reported in specialist conferences; this occasion was not planned to be, and never could be, a chance to learn from, or to criticize, scientific results.

In such a large conference, with 800 or so papers, there are exceptions to every generalization. The exception par excellence on this occasion was the brilliant presentation by Glenn Seaborg of the most beautiful results on the physical properties of elements 104 and 105, principally work from the Berkeley group but representing a strong nationwide collaboration in pure science - who cares whether it is physics or chemistry! The outstanding Russian work on these elements was reported alongside by Flerov of Dubna giving evidence of the remarkable successes achieved there. These papers made good reading on the highest academic standard. Probably there are other exceptional papers with real physics information, but those two took my notice above all.

But what of the conference proper: What is its task and is it doing it? Where does it leave the physicist who made the industry possible? During the last two days of the conference, sessions on special applications of reactors, accelerators and atomic energy processes disclosed a startling range of possibilities. The proposed use of the Los Alamos Meson Factory accelerator ( $800 \mathrm{MeV}$ protons at $0.5 \mathrm{~A}$ ) to investigate tumour treatment by energy selected beams of pi mesons was in the genuine 21 st century tradition, and Milton Klein's survey of existing space applications of radioisotope power and of potential space propulsion systems reminded us that decisions as to which technical advances are ahead of their time and possible application must these days be revised and reviewed rather often. Whole areas of technical application in satellites, lunar and planetary exploration have become real since the last conference.

The main themes of the Conference were clear enough and very relevant to the world situation. The develop-

\section{W. M. Lomer, UKAEA}

ment of power reactors has gone apace in the major developed areas of the world, and now already provides any community wishing to purchase a major power station with a choice of several well-proved systems and suppliers. The selection of the most suitable system depends partly on the characteristics of the power market, the place of the power station within the system and the way the system responds to load variation. But superposed on these objective physical parameters are those of economics - the growth rate of the economy, the rate of interest on capital demanded, the credit guarantees available and so on. Any utility or country wishing to expand its power supplies must now consider nuclear power as a possible economic solution to its particular requirement, and has to contrive somehow to obtain reasonably concrete advice on performance characteristics of the designs offered, and achieved in practice. The Conference proceedings will be a valuable initial guide and survey, however hard it was during the Conference to sift information from opinion.

The next main theme was that the present range of thermal reactors will be supplanted in a few years' time by the fast breeder reactor, producing more fissile fuel than it consumes. The President of the Conference emphasized in his opening talk that the technical strides made in fast reactor technology allowed a confident prediction of an economically successful family of liquid metal cooled fast breeder reactors operating within a decade. This confidence, he pointed out, rested on painstaking technical work by nuclear physicists on the nuclear cross-sections and fission parameters for $\mathrm{Pu}$ in particular, but also on many other elements used in the reactor core structure, by physical metallurgists on the problems of fast neutron damage and the inevitable helium production of the $n-\alpha$ reactions in structural and fuel cladding materials, and on the development by chemists and by 


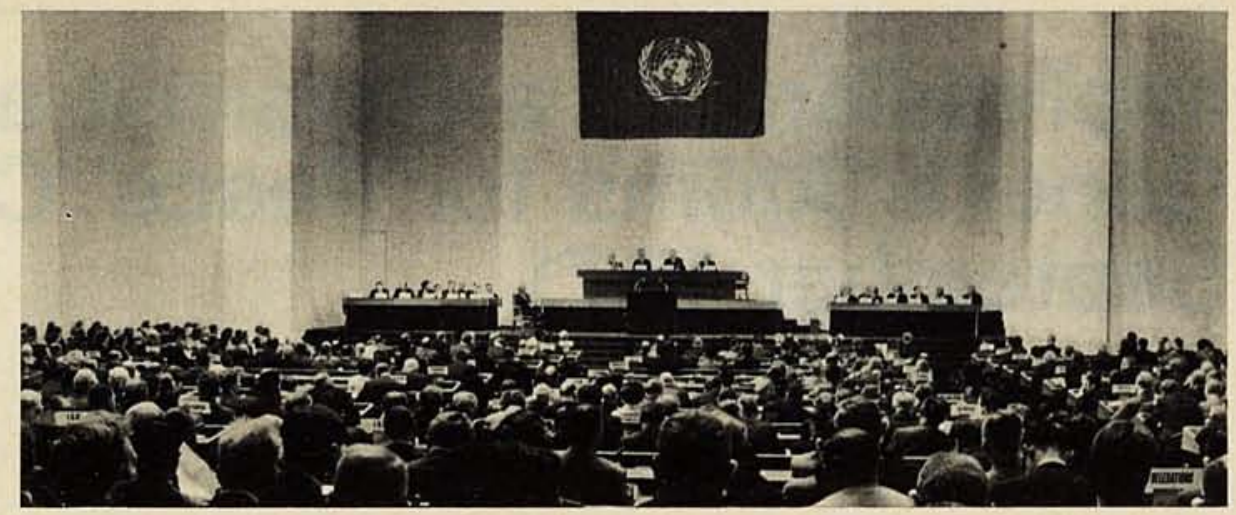

chemical engineers of liquid sodium technology, coated particle fuel production, and compatibility problems. Much remains to be done but the back of the problem appears to be broken. There remains a commercially vital phase of value engineering, of identifying places where the information is weak, and where its improvement could lead to better performance in completed systems. Naturally enough, there was little discussion of just where such effort could best be put.

Next a variation on Theme One, maybe distinct enough to be a theme in its own right. The development potential of thermal reactors is far from exhausted, and two new systems in particular should be noticed - the Steam Generating Heavy Water Reactor designed for flexible load following, and the Advanced Thermal Reactor - helium cooled, graphite coated fuel, graphite moderated, progeny of the ENEA Dragon project sited at Winfrith Heath in UK. Is there a space in the timetable to bring such a system to effective use before the fast reactors take over? Will they be complementary to the fast reactors? Will their remaining development costs be justified against the scale of their deployment? These questions must be answered by economists, power engineers, reactor physicists with a knowledge of fuel cycles, and chemical processors of fuel working out the consequences of different options. An altogether peculiar little arhythmic theme to upset the grand sweep.

And so on to the fourth theme Safety. The decision as to the propriety of siting reactors near cities, installing them on ships, the assessment of risks to the population from reactor accidents, from normal operation and from waste disposal is an onerous technical and political problem. Many papers dealt directly or indirectly with these topics and most of the now standard positions were taken up by protagonists for various siting and disposal policies. However, it was my impression that as the nuclear industry is becoming bigger, the discussions are more seriously seeking agreed positions than hitherto. The dominant fact is that nuclear industry is immensely safety conscious - by both regulation and volition. Apart from aircraft, in no other industry has the assessment of risk by careful quantitative reliability analysis gone so far; enormous numbers of lives could be saved if regulations and procedures of equal rigour were introduced in other industries. The Japanese paper on the nuclear powered ship showed that safety work on the conventional hull and structure raised the cost of those components by a factor two or more relative to normal ship costs. The precautionary wholesomeness testing of irradiated foodstuffs recommended by $\mathrm{WHO} /$ FAO was criticized in an Indian paper which claimed that the tests could with equal logic be said to remain undone in respect of normal cooking processes, and further that more deaths result from protein deficiency than would be hazarded by the widespread consumption of radiation preserved foods. There is a long way to go yet before radioactivity and its associated hazards are thought of with the same detached respect as those of working on high buildings or of crossing roads. Probably one should hope that it may long remain so, yet it was encouraging to a scientist that realistic agreement on hazard assessment seems less remote than before.

Safeguards - the arrangements and agreements for control of fissile material arising from reactor operations - also received due attention, and the possibilities of precise material accountancy were discussed at length. A clearer picture is now emerging of the cost and manpower involved in inspection and control to any agreed precision. It is clear that the cost of guaranteeing the impracticability of diverting nuclear materials to weapons programmes will be considerable but not prohibitive, provided sensible standards are accepted.

The accompanying exhibition
"Atoms for Development" provided a fascinating set of models, working apparatus and information from most of the major technical countries of the world. It was not a commercial exhibition, nor was it fully technical, for those attending the conference really were unlikely to learn much new there. Nevertheless it was startling to see how far we have penetrated into the science-fiction writers' world, with the Russian Lunakhod vehicle, the American isotope powered telemetry transmissions live from the moon, the data on breeder reactors producing more fuel than they consume, and the British stand with its central exhibit showing the kilowatt-hours of nuclear power sent out to date, with the unit and tens digits going by too fast for the eye to follow.

The overall impression was of a thorough stocktaking of an established industry whose costs and successes, risks and failures have been meticulously documented, analysed and regulated unlike any other industry's before. The post facto analysis of this unique record is likely to break new ground in long range economic benefit assessments, for the current estimates at various stages have been quantified on various ground rules, and in the end there will be enough experimental comparison to make or break a number of economists' theories.

\section{Correction}

\section{Computer Documentation : Easy Access to Scientific Knowledge}

In the above article by I. Steinacker, ESRO, published in Europhysics News, Vol. 2, No. 5, mention is made of METADEX tapes. The Institute of Metals, London, informs us that these tapes are produced as a joint venture between the American Society for Metals and The Institute of Metals, London. We regret that we did not give the complete information. 